\title{
Proposal And Development Of The Direct Mail Method "PMCI-DM" For Effectively Attracting Customers
}

\author{
Taku Kojima, Aoyama Gakuin University, Japan \\ Toshiyuki Kimura, Aoyama Gakuin University, Japan \\ Manabu Yamaji, Aoyama Gakuin University, Japan \\ Kakuro Amasaka, Aoyama Gakuin University, Japan
}

\begin{abstract}
Observations of recent changes in the marketing field reveal that a marketing and sales system that places further emphasis on interaction with the customer must be established. The authors conducted a demonstrative study that focused on creating effective direct mail and promotional advertisements for attracting customers to dealers. We consider these strategies to be elemental technologies vital to "forming ties with the customer." Finally, the authors established "PMCI-DM" (Practical use Model of Customer Information for Direct Mail) and applied it at Company A, a foreign-funded automobile sales company. We were thus able to demonstrate this strategy's effectiveness.
\end{abstract}

Keywords: Marketing, Direct Mail, Numeric Simulation, PMCI-DM

\section{INTRODUCTION}

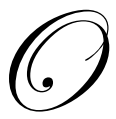

bservation of the recent environmental changes in the marketing field reveals that it is necessary to establish a marketing and sales system that places further emphasis on the ties between the company and the customer and thereby accurately grasps the characteristics and changes in the customers' preferences, regardless of preconceived ideas. In this study, we explore the effectiveness of a new sales strategy that utilizes advertisement and promotional activities. This strategy will contribute to the realization of "strategic marketing" as a corporate management activity by means of accurately grasping the information desired by consumers.

Having said the above, we focused on direct mail, which is a promotional advertisement that effectively attracts customers to dealers as an important elemental technology for the "formation of ties with the customer." More specifically, the authors established a Customer Information practical use Model, "PMCI-DM," as a market creation activity and deployed a promotional advertisement activity using direct mail to effectively attract customers.

\section{IMPORTANCE OF STRATEGIC MARKETING}

When considering current marketing activities, it is no longer enough to carry out an activity in search of short-term strategies only within the marketing and sales divisions, as typified by the 4Ps (Product, Price, Place, and Promotion). It is necessary to carry out a strategic marketing activity that is a core activity of total corporate management where each department inside and outside the company is involved with one another. The key to today's marketing activities lies in a thorough utilization of customer data that goes beyond the conventional customer survey activities. In this age, when the market is saturated with products, is it truly possible to grasp the needs which exist inside the customers" minds and search out their "wants" only by means of survey activities?

In recent times, it has become possible to utilize POS data or electronic transaction data, along with the development of IT, to conduct customer surveys. Therefore, attempts are being made to conduct even more in-depth searches of the ever-changing and growing customer behaviors and preferences through timely analyses and the data mining method to tackle the massive loads of customer purchase history data. The "marketing method" has also 
been clearly changing from the conventional segmentation of customers based simply on explicit customer information, such as their age, sex, size, and type of their company, etc., to "discovery of potential clustering" or use of the "segmentation method for analyzing potential structures" in search of customers" latent desires and preferences.

\section{SALES ACTIVITIES AND PROMOTIONAL ADVERTISEMENT OF AUTOMOBILES}

As a market creation method, quantitatively grasping the effects of promotional advertisements, which is the main method of encouraging sales orders, must be made into a core strategy of marketing and sales activities. However, actual promotional advertisement activities tend to rely on experiential knowledge, in many cases, and therefore, the most desired information by customers is not necessarily provided. Given this background, a more strategic marketing activity is needed these days.

\section{AIDA Theory and Positioning Each Form of Advertising Media}

One model that is useful when considering the effects of an advertisement is to control each step of the physiological transformation, starting from when a person comes into contact with the advertisement until they actually take the action of purchasing the intended product. The prototype of today's advertisement information processing model is the AIDA Model introduced by E. St. Elmo Lewis in 1898. The AIDA Model categorized the purchase behavior psychology of customers into four steps: A (Attention), I (Interest), D (Desire), and A (Action). Putting the first initial of each of these behavioral psychology steps together spells out the acronym AIDA.

Advertising media, such as TV, commercials, or newspapers, are mainly used by manufacturers of products, whereas newspaper insert advertising or direct mail are promotional advertisements primarily used by sales dealers and shops. Above all, it was thought that debaters were effective for the making of bond of a visitor and the dealers and, besides, paid my attention to the direct mail which contributed to be effective in attracting customers.

\section{Previous Studies}

A direct mail study entitled "Creating the Direct Mail Method "SAM-DM" to Effectively Attract Customers" was performed to establish precedent. This study investigated customer awareness at the time of purchase and identified what information customers needed. As a result, the authors established a new approach to the concept of creating direct mail that uses statistical techniques to determine what kind of information is sent out, rather than relying on conventional rules of thumb. Figure 1 illustrates this Scientific Approach Method, or "SAM-DM".

\section{Importance and Relevant Problems of Direct Mail}

Promotional advertising activities that utilize TV and commercials have an effect upon the first step of AIDA Theory - Attention - while newspaper insert advertisements cause a psychological transformation from Interest to Desire. Consequently, newspaper insert advertisements or direct mail, which are used mainly by sales dealers as the advertising media for attracting customers, make vital contributions to the customer attraction rate. That is to say, the role of sales dealers based in the local community is vital to forming ties with the customers. Direct mail, in particular, can get the information that you want to convey to the precise customers with pinpoint accuracy and appeal to them directly. This positions it as an important advertising medium for improving the customer attraction effect. Therefore, direct mail is an effective advertising medium for forming relationships between the automobile sales dealers and their customers.

The direct mail means a little how the dealers can approach for a customer individually. However, the information that customers need and voice from the shop floor are not reflected under the present conditions by a direct mail. This occurs when the head office and dealers cannot utilize customer information enough. In addition, even as for the decision-making stage for whom to send a completed direct mail, a salesman decides a target customer from experience and wisdom. As a result, it is also common that direct mail cannot reach a person who needs, but instead reaches the person who doesn't need. For that reason, it is given that the taste of the customer and the difference of the attributes according to the lifestyle cannot be grasped. There is also the problem that labor and time matter when choosing target customers who should be sent a direct mail. In this paper, the authors make a 
segment of the attributes of the customers by constructing a simulation system, choosing target customers for sending a direct mail that provides a list of customers who have a high possibility of visiting dealers.
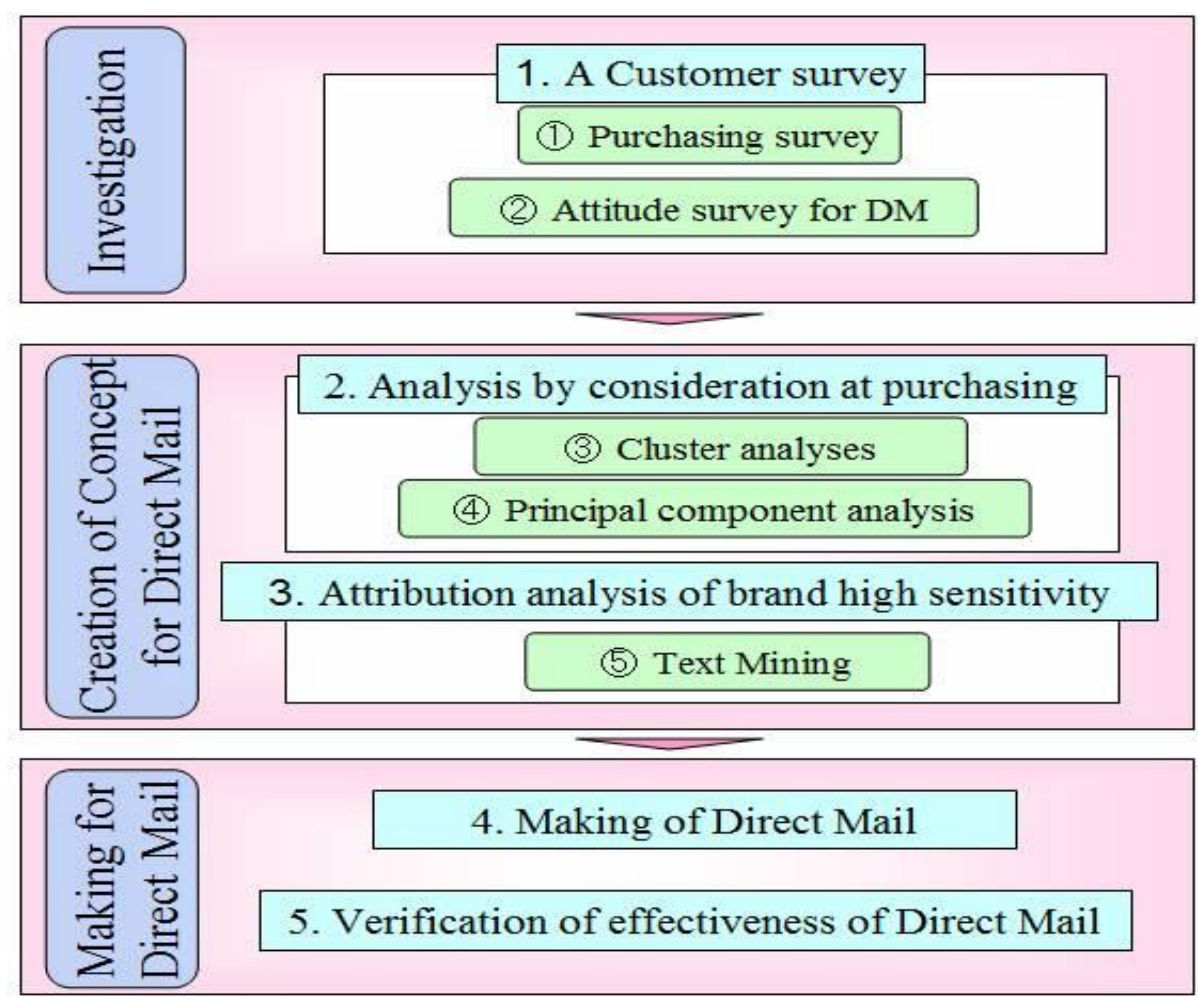

Figure 1: Scientific Approach Method "SAM-DM"

\section{THE PMCI-DM MODEL FOR UTILIZING CUSTOMER INFORMATION}

Companies that use advertising media simply to communicate their own objectives to consumers do not reflect customer needs in their promotional activities. Companies must carry out promotional activities that operate from the customer's point of view. The criterion for these activities is whether information that the customer needs is being distributed when the customer wants it in a timely manner. Based on consultations with both domestic and foreign-funded auto dealers, it has been determined that when companies send out information is not when customers actually want the information. With the help of auto dealers, the authors collected profile data on customers who visited various dealer events. This allowed us to determine the specific characteristics of those customers to whom direct mail should be sent. Figure 2 outlines the six steps needed to implement PMCI-DM, a strategic model for distributing direct mail.

\section{Grasping Visiting Customer Trends}

\section{STEP 1: Company Consultation Meetings and Data Collection}

Consultation meetings were held with auto dealers (one domestic and one foreign-funded) to discuss the customer attraction rate for direct mail. Though there is some room for error in the data, the results of the investigation showed around a $2 \%$ attraction rate for direct mail. In considering cost performance, dealers hoped to double this rate. Dealers also indicated that they felt they were not making the best use of their customer information.

In general, customer profile data was gathered from those who came to the dealer for model-specific events. Specifically, data on gender, age, occupation, and current vehicle model was collected. 


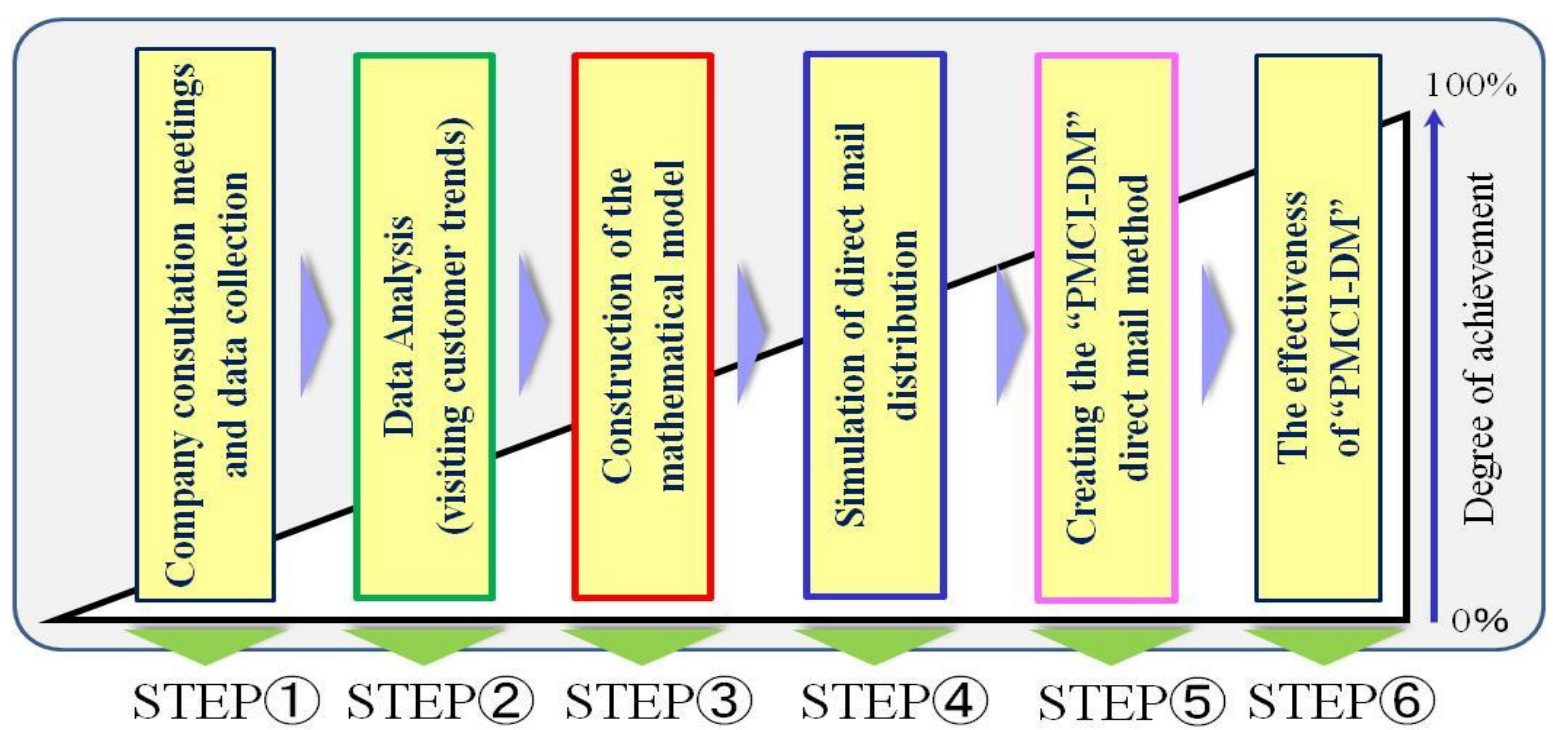

Figure 2: Steps for Implementing PMCI-DM

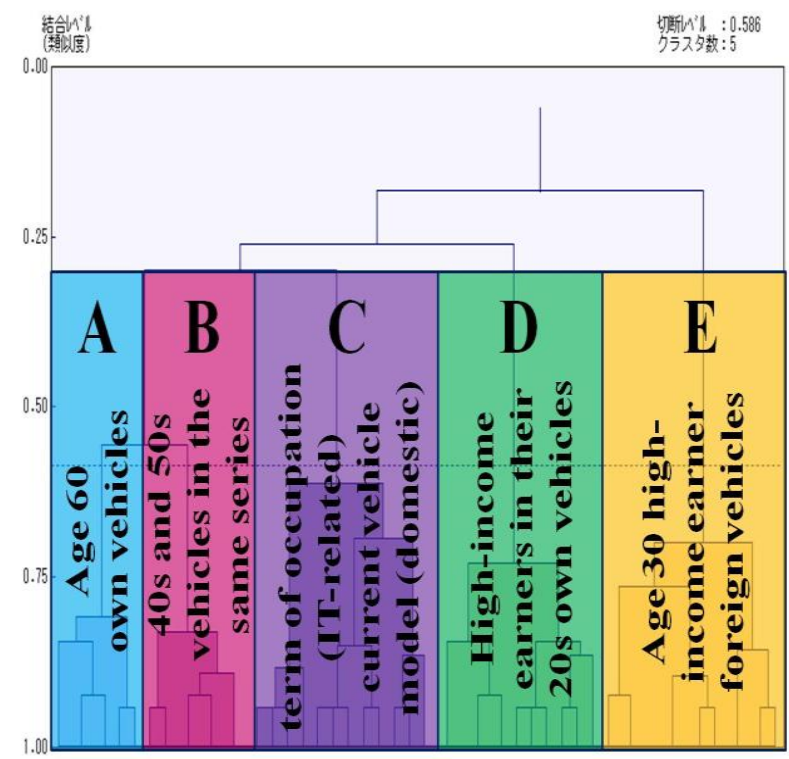

Figure 3: Cluster Analysis of Visiting Customer Characteristics

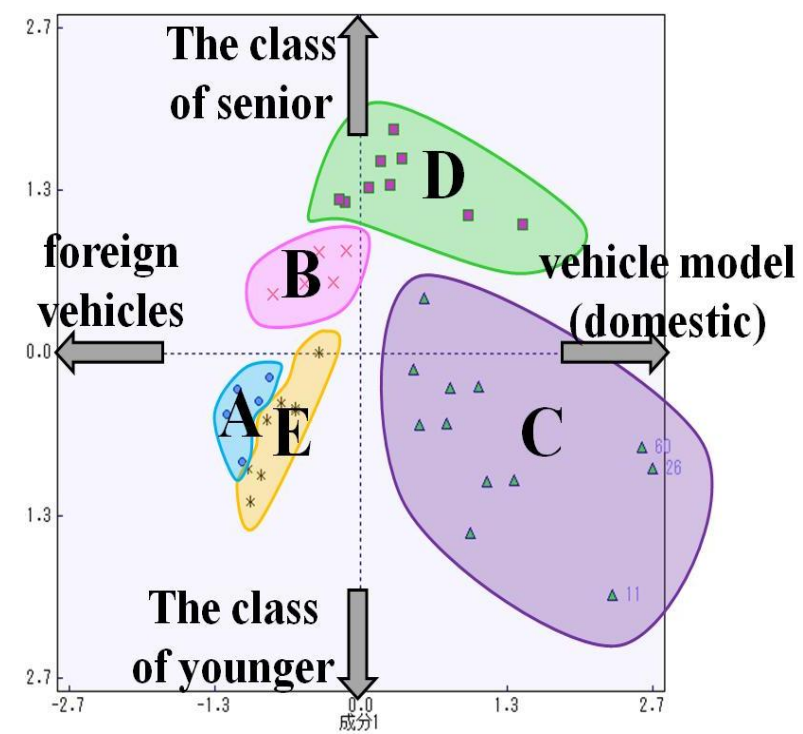

Figure 4: Type 3 Quantification Analysis of Customer Characteristics

STEP 2: Analyzing Data on Visiting Customer Trends

By analyzing the raw data provided by dealers, it was possible to identify the type of customer who visited the dealer for each vehicle model. Cluster analysis and Type 3 quantification were the analysis methods used. The cluster analysis results for vehicle model A are shown in Figure 3. The analysis resulted in five groups labeled A through E. Figure 4 shows the results of the Type 3 quantification analysis.

In looking at the characteristics of each group, we can see that Group A consists of customers age 60 and over who already own vehicles from Company A. Group B customers are in their 40s and 50s and already own 
vehicles in the same series as those on display at the event. While diverse in terms of age, Group C was consistent in terms of occupation (IT-related) and current vehicle model (domestic). Group D consists of high-income earners in their 20s who already drive Company A-brand vehicles. Finally, Group E consists of high-income earners in their 30s who currently drive foreign vehicles.

As Figures 3 and 4 indicate, characteristics of customers who visited the dealer can be quantitatively classified into like groups based on factors, such as age, current vehicle model, and occupation. Of course, the characteristics of visiting customers will vary for each event based on the vehicle models that are featured. Accordingly, companies must design marketing activities that are statistically-based and make effective use of customer information if they are to establish a leading sales framework among competitors.

We will next look at formulating a system to make actual use of this customer information.

\section{Formulating a Predictive Simulation System}

\section{STEP 3: Mathematical Model for Solving Combinatorial Optimization Problems}

Formula(i) below was created as a model formula for selecting customers to whom direct mail is to be sent using data for customers visiting each auto dealer (customer group). Additionally, formula(ii) is used to develop constraints for sales and marketing strategies.

$$
\begin{aligned}
& \sum_{m \in M} W^{m}\left(\sum_{j \in J} f_{j}^{m} x_{j}-C R^{m}\right)^{2} \\
& L^{m} \cdot C \leq \sum_{j \in J} f_{j}^{m} x_{j} \leq H^{m} \cdot C, m \in M \text { (i) }
\end{aligned}
$$

$J \quad$ Customer group

$M \quad$ Life stages group

$x_{j} \quad$ Included/not included in direct mail target group

$C \quad$ Total number of customers targeted for direct mail

$R^{m} \quad$ Actual results for customers with life stages $m \in M$ in direct mail target group

$W^{m} \quad$ Weighting for customers with life stages $m \in M$ in direct mail target group

$f_{j}^{m} \quad$ life stages $m \in M$ apply to/do not apply to customer group $j \in J$

$H^{m} \quad$ Upper-limit for ratio of customers with life stages $m \in M$ in direct mail target group

$L^{m} \quad$ Lower-limit for ratio of customers with life stages $m \in M$ in direct mail target group

The purpose of this numeric simulation is to calculate $x_{j}$ that satisfy formula(i) and formula(ii).

\section{STEP 4: Simulation of Direct Mail Distribution}

In this paper, the profile data (gender/age/occupation/possession of a car model) of a customer are recorded in a system. The tendencies of the customers from the profile data are different for every car model to become the target at sale events. Therefore, when it is simulated, the tendencies of customers, by statistical techniques, are replaced with the ratio and are reflected in the system.

As a result, highly attracted customer effects are derived according to the direct mails sent to each customer for every sale event. In other words, it is one of the tools helping with decision support of the business activities that rely on empirical knowledge. 


\section{Implementing PMCI-DM}

\section{STEP 5: Creating the PMCI-DM Direct Mail Method}

In the above discussion, we have given examples of how customer information can be utilized through statistical methods in each step. By employing the scientific method in this way, advertising and promotional activities can be carried out strategically rather than based on moment-to-moment needs and observations. Figure 5 shows a model "PMCI-DM" to develop a direct mail strategically. This model consists of the following four steps.

Step 1: In this model, questionnaires are performed as collection of customer information at dealers and the data are accumulated in the system.

Step 2: Analysts analyze the data which was provided by statistics technique (cluster analysis, quantification 3) and catch the tendency of the guest.

Step 3: The tendency is replaced with numerical value and reflected in a system.

Step 4: The result by simulation is used at the time of direct mail delivery.

Then, by consolidating a series of such processes, "PMCI-DM" was established as a model for developing a direct mail strategically.

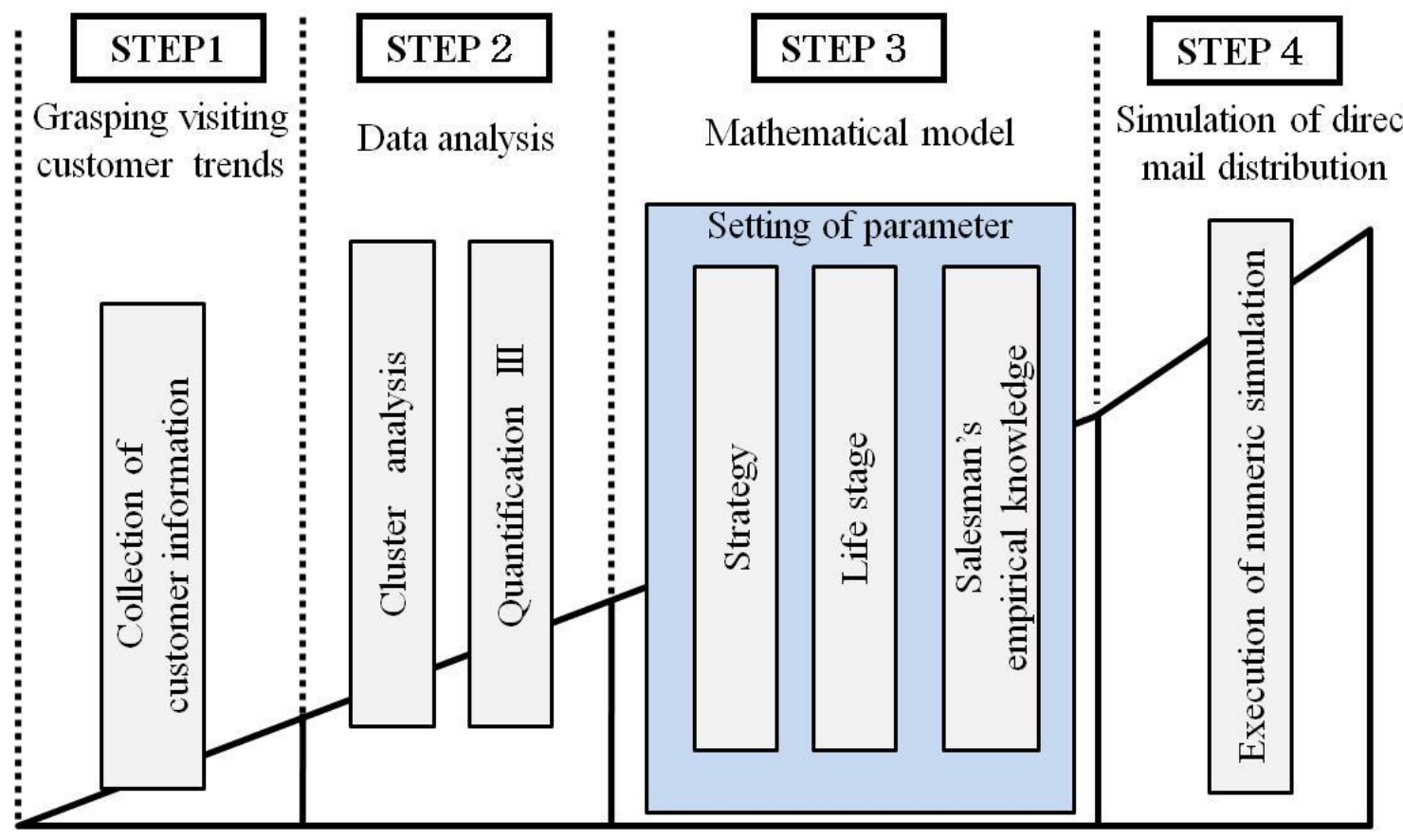

Figure 5: PMCI-DM Model to Utilize Customer Information

STEP 6: The Effectiveness of "PMCI-DM"

The authors develop "PMCI-DM", which they suggest now in Company A. The customer information that dealers hold is reflected in a system and then the profile data of the guests from every event is analyzed and grasps visiting customers' trends. Finally the dealers reflect a result of the analysis in a system and simulate it. The average coming to the dealer's ratio increased from 3.3\% to 4.5\% through PMCI-DM. From the given result, we proved the effectiveness of "PMCI-DM". 


\section{CONCLUSION}

In this paper, the authors suggested a model, "PMCI-DM", to develop a direct mail strategically by utilizing customer information. It may be said that this model is effective in content and the design creating of the direct mail, which matched a customer, as well as decision support at the time of the direct mail delivery. Also, the authors let the model apply to Company A, which is a car manufacturer. In the future, it is expected that a new promotional advertising strategy, that reflects the potential needs of customers in the advertisement by means of "scientific marketing", will be established.

\section{AUTHOR INFORMATION}

Taku Kojima is a graduate student of the College of Science and Engineering at Aoyama Gakuin University.

Toshiyuki Kimura received his Master of Engineering degree from the College of Science and Engineering at Aoyama Gakuin University.

Manabu Yamaji is a research associate in the College of Science and Engineering at Aoyama Gakuin University, Japan. He received his Master of Engineering degree in Graduate School of Information Systems at University of Electro-Communications in 1999. His current research and teaching interests are in the general area of production engineering. In particular, he is interested in Total Quality Management, Computer Aided Engineering.

Kakuro Amasaka is a Professor in the College of Science and Engineering at Aoyama Gakuin University, Japan. $\mathrm{He}$ received his Ph.D. degree in Precision Mechanical and System Engineering, Statistics and Quality Control at Hiroshima University in 1997. His current research and teaching interests are in the general area of production engineering. In particular, he is interested in New JIT. He is a member of POMS and EurOMA.

\section{REFERENCES}

1. Amasaka, K., (2005), Constructing a Customer Science Application System "CS-CIANS"- Development of a Global Strategic Vehicle "Lexus" Utilizing New JIT -, WSEAS Transactions on Business and Economics, Issue 3, Vol. 2, pp.135-142.

2. Amasaka, K., (2007), The Validity of Advanced TMS, A Strategic Development Marketing System-Toyota's Scientific Customer Creative Model Utilizing New JIT-, The International Business \& Economics Research Journal, Vol.6 No.8, pp.35- 42.

3. Amasaka, K., (2007), The Validity of TDS-DTM : A Strategic Methodology of Merchandise Development of New JIT -Key to the Excellent Design "LEXUS", The International Business \& Economics Research Journal, Vol.6, No.11, pp.105-115.

4. $\quad$ Amasaka, K., (2004), Science SQC, New Quality Control Principle Springer.

5. Nakamura, M., Kuniyoshi, M., Yamaji, M. and Amasaka, K., (2008), Proposal and Validity of the Merchandise Planning Business Model “A-POST”, International Symposium on Management Engineering, pp.232-239.

6. Amasaka, K. and Osaki, S., (1999), The Promotion of New Statistical Quality Control Internal Education in Toyota Motor -A Proposal of "Science SQC" for Improving the Principle of TQM, European Journal of Engineering Education, Research an Education in Reliability, Maintenance, Quality Control, Risk and Safety, Vol.24, No.3, pp.259-276.

7. Shimizu, K., (2004), Theory and Strategy of Advertisement. Sousei publishers. (in Japanese)

8. Amasaka, K.(Editor), (2007), New Japan Model, Science TQM, Theory and Practice of Strategic Quality Management, Maruzen. (in Japanese)

9. Amasaka, K., (2007), The Validity of Advanced TMS, A Strategic Development Marketing System Utilizing New JIT, The International Business \& Economics Research Journal, Vol.6, No.8, pp.35-42.

10. Kimura, T., Yamaji M. and Amasaka K., (2007). A Study of "Scientific Approach Method for Direct Mail, SAM-DM" Effectiveness of Attracting Customers Utilizing Advanced TMS, Proceedings of the $5^{\text {th }}$ Asian Quality Congress, Hyatt Regency, Incheon, Korea, pp.938-945.

11. Frishammar, J., (2005), Managing information in new product development : A literature Review, International Journal of Innovation and Technology Management, Vol. 2, No.3, pp.259 - 275. 
12. Fleisher, C., Wright S., and Allard, H., (2008), The Role of Insight Teams in Integrating Diverse Marketing Information Management Techniques, European Journal of Marketing, Vol.42, No.6/7, pp.836-851.

\section{NOTES}

